\title{
Does Pre-Existent Gastroduodenal Ulcer Increase Gastrointestinal Bleeding after Cardiac Surgery?
}

\author{
Mahdi Aithoussa*, Ayou Abeti, Abdou Abdessamad, Younes Moutakiallah, Fouad Nya, Mohamed \\ Drissi and Abdelatif Boulahya
}

Department of cardiovascular Surgery, Rabat Medical School, Mohammed 5 University, Morocco

*Corresponding author: Mahdi Aithoussa, Department of cardiovascular Surgery, Rabat Medical School, Mohammed 5 University, Morocco, E-mail: mahdiaithoussa@yahoo.fr

\begin{abstract}
Objective: Controversy persists about the role of pre-existent gastro duodenal ulcer as a risk factor of upper gastro intestinal bleeding after cardiac surgery. This study aims to verify this hypothesis.
\end{abstract}

Patients and methods: We retrospectively analyzed data of alla patients who underwent open heart surgery between 1994 and 2012. Patients with previous gastro duodenal ulcer ( $\mathrm{n}=87$ ) (GDU) compared to those without GDU ( $\mathrm{n}=1986)$.

Results: Patients with GDU are older than control group $(p=0,000)$ and have more frequently cardiovascular risk factors than others. Coronary bypass grafting (CABG) was performed more in patients with a history of GDU $(p=0,039)$. Postoperative complications are frequently reported also. Additionally they have developed upper gastro intestinal bleeding (UGIB) more than control group $(5,7 \%$ vs $0,8 \%, p=$ 0,002).

Conclusion: Pre-existent gastro duodenal ulcer should be the risk factor of upper GIB and optimal management requiring endoscopic diagnosis and treatment before CPB should prevent digestive hemorrhage.
Received date: January 29, 2016

Accepted date: February 09, 2016

Published date: February 12, 2016

Citation: Aithoussa, M., et al. Does Pre-Existent Gastroduodenal Ulcer Increase Gastrointestinal Bleeding after Cardiac Surgery? (2016) J Gastrointest Disord Liver Func 2(1): 43- 46.

Keywords: Gastro duodenal ulcer, Cardiac, Surgery, Upper gastro duodenal bleeding

DOI: $10.15436 / 2471-0601.16 .762$

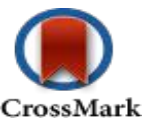

\section{Introduction}

Stress ulcerations of the stomach accompanied by massive hemorrhage are common in cases of trauma, sepsis, shock massive burns, prolonged use of steroid and non steroid anti-inflammatory drugs ${ }^{[1,2]}$. The large practice of cardiac surgery has increased the occurrence of digestive complications especially upper digestive tract bleeding. Although infrequent it is associated with significant morbidity and mortality ${ }^{[3-5]}$. Acute bleeding is the most common complication of peptic ulcer disease and about half of cased are causes by gastric and duodenal ulcers ${ }^{[6,7]}$. Many factors were identified as predictive of gastro intestinal bleeding after open heart surgery. There are conflicting opinions about the role of pre-existing peptic ulcer disease as a cause of postoperative hemorrhage ${ }^{[8,9]}$.

In our knowledge, the are no few studies investigating the impact of previous gastric ulcer as increasing the risk of UGD bleeding after cardiopulmonary bypass (CPB).

We hypothesized that previous gastroduodenal ulcer would be more predictor and cause gastrointestinal bleeding after open heart surgery. 


\section{Patients and Methods}

\section{Study population}

The present retrospective study was conducted at author's institution and approved by local medical ethic committee. All patients who had a history of gastroduodenal ulcer and underwent cardiac surgery were compared to other without a history of pre-existing gastroduodenal ulcer. These medical informations were collected using our cardiac surgery data base of patients who underwent various types of cardiac surgery between January 1994 and December 2012. These patients underwent coronary artery bypass grafting (CABG), valvular surgery, combined surgery, thoracic aortic surgery and surgical correction of adult congenital heart defects.

A history of previous gastroduodenal ulcer included questions about the symptoms, use of Histamine 2 Receptor Antagonist (H2rA) or Proton Pump inhibitors (PPIS) or non steroidal anti-inflammatory drugs, smoking and alcohol abuse. But diagnosis might be confirmed by endoscopy.

In our institution, when patient had a history of previous peptic ulcer, we performed systematically endoscopy before cardiac surgery to confirm the recovery and good scar. But if the endoscopic appearance suggested the abnormalities, the patient was confided to gastroenterologist for management and the cardiac surgery was referred until the endoscopy control showed the good gastric appearance. Cardiac surgery was performed under CPB using a roller pump and membranous oxygenation. Blood temperature was maintained up to $32^{\circ} \mathrm{C}$. Before 2000 , patients received for stress ulcer $\mathrm{H} 2 \mathrm{RA}$ for the operative day until 1 month. After 2000, the routine stress ulcer prophylaxis used PPI intravenously for 2 days (40mg x 2) followed by $20 \mathrm{mg}$ peros for 1 month.

\section{Statistical analysis}

Baseline clinical characteristics and operative data were analyzed for both previous GPD cases and controls. Analysis was performed with SPSS software version 19.0 SPSS Inc, Chicago, USA). Continuous variables were reported as mean \pm standard deviation or median and ranges). Categorical variables were expressed as proportions. For nominal variables, the Chi-square test or Fisher's exact test were used to compare the groups. Continuous variables were analyzed using Student's $\mathrm{t}$ test for normal distributions and U Mann Whitney's test for non-normal distributions. $\mathrm{P}$ value $<0,05$ was considered to be statistically significant.

Gastrointestinal bleeding was defined as hematemesis melena, nasogastric tube aspiration of blood material, hamatochezia on rectal examination, or the combination of guaiac positive stool on occult blood testing and significant decline in the hemoglobin level $(<10 \mathrm{~g} / \mathrm{l})$

\section{Results}

A total of 2073 adult patients were included in the present retrospective study. We have identified 87 patients $(4,19 \%)$ who had a history of gastro duodenal ulcer (GDU) at the time of cardiac surgery. The demographic profile of patients is shown in table 1.

\begin{tabular}{|l|c|c|c|}
\hline \multicolumn{1}{|c|}{ Variable } & $\begin{array}{c}\text { without } \\
\text { previous } \\
\text { GH n=1986 }\end{array}$ & $\begin{array}{c}\text { with } \\
\text { previous } \\
\text { GU n=87 }\end{array}$ & P value \\
\hline Age (y) & $47,7 \pm 14$ & $53,8 \pm 11,7$ & $<0,001$ \\
\hline Sex Male/Female & $1213(61 \%)$ & $71(81,6 \%)$ & $<0,001$ \\
\hline NYHA III-IV & $897(45 \%)$ & $37(42,5 \%)$ & 0,6 \\
\hline Ces III-IV & $236(11,8 \%)$ & $10(11,5 \%)$ & 0,9 \\
\hline Heart failure & $165(8,3 \%)$ & $12(13,8 \%)$ & 0,073 \\
\hline Diabetes Mellitus & $377(18,9 \%)$ & $24(27,5 \%)$ & 0,047 \\
\hline Chronic renal failure & $113(5,7 \%)$ & $9(10,3 \%)$ & 0,07 \\
\hline COPD & $123(6,2 \%)$ & $13(14,9 \%)$ & 0,001 \\
\hline CVA & $83(4,2 \%)$ & $1(1,1 \%)$ & 0,26 \\
\hline AF & $578(29 \%)$ & $18(20,6 \%)$ & 0,09 \\
\hline CTI & $0,55 \pm 0,07$ & $0,54 \pm 0,06$ & 0,82 \\
\hline Coronary artery disease & $551(27,7 \%)$ & $33(37,9 \%)$ & 0,039 \\
\hline Valvular disease & $1284(64,6 \%)$ & $48(55 \%)$ & 0,07 \\
\hline Combined V+C & $44(2,2 \%)$ & $3(3,4 \%)$ & 0,24 \\
\hline Aortic disease & $33(1,7 \%)$ & $0 \%$ & 0,26 \\
\hline LVEF (\%) & $56,8 \pm 12$ & $55,5 \pm 12,5$ & 0,32 \\
\hline LVEF $\leq 40 \%$ & $258(13 \%)$ & $14(16 \%)$ & 0,4 \\
\hline SPAP mmHg & $49,7 \pm 19,3$ & $48,6 \pm 18,9$ & 0,72 \\
\hline Euroscore & $2,8 \pm 2,8$ & $3,3 \pm 3,7$ & 0,28 \\
\hline Redo Surgery & $208(10,4 \%)$ & $9(10,3 \%)$ & 0,9 \\
\hline HTA (\%) & $365(18,3 \%)$ & $26(29,8 \%)$ & 0,007 \\
\hline Dyslipidemia $(\%)$ & $280(14 \%)$ & $19(21,8 \%)$ & 0,045 \\
\hline Smoking (\%) & $676(34 \%)$ & $48(55 \%)$ & $<0,001$ \\
\hline
\end{tabular}

There were significant differences between the two groups with regard to age, sex and cardiovascular risk factors. Patients with preexistent (preexistent) GDU are older than control group $(53,8 \pm 11,7$ years vs $47,7 \pm 14$ years, $p<0,001)$.

Some points were noted among the patients with history of ulcer disease. $55 \%$ of patients with GDU were either current or ex-smokers vs $34 \%$ in control group $p=0,000$. Diabetes mellitus (DM), hypertension (HT) and dyslipidemia were also common in patients with GDU. DM ( $\mathrm{p}=0,0047)$, HT $(\mathrm{p}=0,007$ and dyslipidemia $(p=0,045)$ (table 2$)$.

Table 2:

\begin{tabular}{|l|c|c|c|}
\hline Variable & $\begin{array}{c}\text { without } \\
\text { previous } \\
\text { GH n=1986 }\end{array}$ & $\begin{array}{c}\text { with } \\
\text { previous } \\
\text { GU n=87 }\end{array}$ & $\begin{array}{c}\text { P } \\
\text { value }\end{array}$ \\
\hline No elective surgery & $93(4,6 \%)$ & $7(5 \%)$ & 0,19 \\
\hline CPB time (min) & $100 \pm 42$ & $105,7 \pm 41,4$ & 0,23 \\
\hline Cross clamp time (min) & $66,7 \pm 31$ & $65,5 \pm 26$ & 0,68 \\
\hline Mean surgical time (min) & $\begin{array}{c}208,8 \pm \\
61,4\end{array}$ & $219 \pm 72$ & 0,058 \\
\hline Mechanical ventilation (h) & $8(6-18)$ & $9(6-17,7)$ & 0,48 \\
\hline MV up to 48hours & $133(6,7 \%)$ & $10(11,5 \%)$ & 0,088 \\
\hline ICU stay (hours) & $46(24-48)$ & $46(37-57)$ & 0,21 \\
\hline Postoperative stay (days) & $13 \pm 12$ & $14,4 \pm 11,7$ & 0,31 \\
\hline Blood last up to normal/24h & $172(8,6 \%)$ & $7(8 \%)$ & 0,84 \\
\hline Vasoactive drug (\%) & $266(13,4 \%)$ & $17(19,5 \%)$ & 0,1 \\
\hline IABP & $100(5 \%)$ & $7(8 \%)$ & 0,21 \\
\hline
\end{tabular}




\begin{tabular}{|l|c|c|c|}
\hline LOS & $192(9,6 \%)$ & $14(16 \%)$ & 0,05 \\
\hline Postoperative renal failure & $132(6,6 \%)$ & $12(13,7 \%)$ & 0,011 \\
\hline UGI Bleeding & $17(0,8 \%)$ & $5(5,7 \%)$ & 0,002 \\
\hline Preoperative MI & $91(4,5 \%)$ & $8(9,2 \%)$ & 0,06 \\
\hline CVA & $22(1,1 \%)$ & $3(3,4 \%)$ & 0,08 \\
\hline MOF & $78(3,9 \%)$ & $7(8 \%)$ & 0,09 \\
\hline RBC transfusion & $690(34,7 \%)$ & $41(47,1 \%)$ & 0,024 \\
\hline 30 day mortality & $116(5,8 \%)$ & $14(16,1 \%)$ & $<0,001$ \\
\hline
\end{tabular}

Coronary artery bypass grafting (CABG) was performed more in patients with GDU when compared to control group $37,9 \%$ vs $27,7 \% \mathrm{p}=0,039$.

On other hand, no significant differences were observed between the groups in term of operative parameters (emergency surgery, CBP time, aortic cross clamp time, mechanical ventilation time, ICU stay and post-operative hospital stay).

Regarding postoperative complications, we noted that patients with GDU were significantly more likely to develop low output syndrome (LOS) $(13,7 \%$ vs. $9,6 \%, p=0,05)$, renal insufficiency $(13,7 \%$ vs. $6,6 \%, p=0,011)$. Other major complications (perioperative myocardial infarction, cerebral vascular accident CVA, multi organ failure MOF) were more prevalent in the GDU group, but it did note rich statistical significance. However, patients with a history of GDU developed upper gastrointestinal bleeding more than control group $(5,7 \%$ vs. $0,8 \%$ $, p=0,002)$. The mean interval between cardiac surgery and the onset of upper GIB was $13 \pm 5$, 5days. Management of upper GIB has changed in our institution. Since 2000, endoscopic therapy is generally recommended as the first line treatment. Medical therapy included after stopping anticoagulation, red blood transfusion and intravenous PPIs until the bleeding control (table 3).

Table 3:

\begin{tabular}{|l|c|c|}
\hline Variable & OR (95\% IC) & P Value \\
\hline Age & $1,03\left(1,01 \_1,05\right)$ & $<0,001$ \\
\hline Gander & $2,8\left(1,6 \_4,9\right)$ & $<0,001$ \\
\hline Diabete Mellitus & $1,6\left(1 \_2,63\right)$ & 0,049 \\
\hline HTA & $1,9\left(1,2 \_3,03\right)$ & 0,008 \\
\hline Dyslupidemia & $1,7\left(1 \_2,8\right)$ & 0,047 \\
\hline Smoking & $2,38\left(1,54 \_3,66\right)$ & $<0,001$ \\
\hline COPD & $2,66\left(1,43 \_4,9\right)$ & 0,002 \\
\hline RBC transfusion & $1,63\left(1,06 \_2,5\right)$ & 0,025 \\
\hline
\end{tabular}

In hospital mortality increased more in patients with preexistent GDU 14 deaths $(16,1 \%$ vs. $5,8 \%, \mathrm{p}<0,001)$.

\section{Discussion}

Our study showed that pre-existent gastro duodenal ulcer would be a significant predictor of cardiac surgery, also we found correlation between a history of previous peptic ulcer disease and upper GIB $(p<0,001)$.

Bleed from upper gastro intestinal tract is the most common gastro intestinal complication following cardio thoracic surgery ${ }^{[10-12]}$. Van der Voort and Zandstra ${ }^{[13]}$ reviewed the available publishing literature before 2000 concerning the incidence of upper GIB and found it occurring in $0,45-2 \%$. In numerous recent published papers, we noted that upper GIB incidence did not decline through the years despite constant improvements in medical management. In one study, gastrointestinal hemorrhage a count nearly $29 \%$ of all gastro intestinal complications following cardio thoracic surgery ${ }^{[14]}$.

In the present study upper GIB after cardiac surgery showed an overall incidence of $0,1 \%$. Previous studies have reported that the acute peptic ulcer after cardiac surgery complicated by gastro intestinal hemorrhage was associated with a mortality rate ranging from $1 \%$ to $22 \%{ }^{[15,16]}$.

The most common etiologies of UGIB are gastro duodenal ulceration and gastric erosion ${ }^{[17-20]}$.

A peptic ulcer is a defect in the gastric and duodenal wall that extends through the muscularis mucosae. The pathogenesis of mucosal lesions and multifactorial including psychological and physicogical stress ${ }^{[19,21]}$.

Stress ulceration has been attributed to ischemia and/or reperfusion injury of the splanchnic territory and endotoxiemia leading to gastro duodenal mucosae damage ${ }^{[22,23]}$. The principal factor implicated in cardiac surgery is reduced systemic blood flow, which lead toinappropriate oxygen delivery and energy deficit. This ischemic condition contributes to gastric mucosal acidity and increased cellular permeability ${ }^{[24]}$ there are controversial opinions about the role of pre-existing peptic ulcer disease as a cause of post-operative hemorrhage ${ }^{[8,9]} . \mathrm{Kal}^{[25]}$ and Lebovics $^{[26]}$ found that patients with previous history of peptic ulcer disease may be at higher risk for developing an upper gastro duodenal perforation or hemorrhage following cardiac surgery.

In other reports, there is no significant evidence that a previous history of peptic ulcer disease would be correlated with increased risk for gastric hemorrhage ${ }^{[8]}$.

Our results are in accordance with this reports and we found that patients with a history of previous PUD experienced a higher rate of postoperative bleeding $(5,7 \%$ vs $0,8 \% \mathrm{p}=0,002)$. Many available studies which identify risk factors associated with UGIB after CPB are published in the literature.

The relationship between upper gastro intestinal bleeding and renal insufficiency, low output syndrome, smoking, diabetes mellitus, blood transfusion has been documented in various studies ${ }^{[11,27-30]}$. All these factors are more frequent in our cases compared to control group. Similarly, Rey et al ${ }^{\left[{ }^{[3]}\right.}$ have observed that digestive bleeding is frequent in patients who underwent coronary artery bypass graft $(\mathrm{CABG})$ than in the cases of heart valve surgery. Our data are in a great accordance with this report (CABG: $37 \%$ in cases with previous GUD vs $27,7 \%$ in control group $\mathrm{p}=0,039)$.

Several studies have examined pharmacological stress ulcer prophylaxis in patients undergoing cardiac surgery ${ }^{[}$.

The benefit of histamine 2 receptor antagonists (H2RA) to protect the stomach is still discussed. Many investigators suggested that H2RA were effective in reducing surgical stress response and preventing clinical gastric hemorrhage.

Our study is limited first by its retrospective nature, second, the association between previous gastro duodenal ulcer and high risk of Upper gastro intestinal hemorrhage may be interpreted carefully because in patients with previous gastro duodenal ulcer who have developed upper gastro intestinal bleeding, it is difficult to recognize that bleed is due to another ulcer.

Second, it is possible also that some patients might 
have peptic ulcer disease without having pain and they were included in control group without knowing it.

\section{Conclusion}

Our result showed a clear correlation between pre-existent peptic ulcer disease and UGIB after CPB; but prospective studies are needed to support this hypothesis. In the meantime, appropriate management including preoperative endoscopy, routine stress ulcer prophylaxis, and avoiding adverse events in postoperative period should be benefit for those patients.

\section{Reference}

1. Fitts, C.D., Cathcart, R.S. Ariz, C.P., et al. Acute gastrointestinal tract ulceration: Cushing's ulcer, steroid ulcer, Curling's ulcer and stress ulcer (1971) Ann Surg 37(4): 218-223.

2. Langman, M.J. Epidemiological evidence of aspirin and acute gastrointestinal bleeding. (1970) Gut 11: 627-634.

3. Nalysnyk, L., Fahrbach, K., Reynolds, M.W., et al. Adverse events in coronary artery bypass graft (CABG) trials: A systematic review and analysis. (2003) Heart 89(7): 767-772.

4. Bhat, M., Larocque, M., Amorim, M., et al. Prediction and prevention of upper gastrointestinal bleeding after cardiac surgery: A case control study. (2012) Can J Gastroenterol 26(6): 340-344.

5. Krasna, M., Flancbaum, L., Trooskin, S., et al. Gastrointestinal complications after cardiac surgery. (1988) Surgery 104(4): 773-780.

6. Laine, L., Peterson, W.L. Bleeding peptic ulcer. (1994) N Engl J Med 331(11): 717-727

7. Encarnacion, C.E., Kadir, S., Beam, C.A., et al. Gastrointestinal bleeding: treatment with gastrointestinal arterial embolization. (1992) Radiology 183(2): 505-508.

8. Della Ratta, R.K., Corapi, M.J., Horowitz, B.R., et al. Risk of postoperative upper gastrointestinal tract hemorrhage in patients with active peptic ulcer disease undergoing non-ulcer surgery. (1993) Arch Intern Med 153(18): 2141-2144.

9. Chigot, J.P., Bitker, M., Chalgadian, R., et al. [Abdominal complications of heart surgery]. (1981) Arch Mal Coeur vaiss 74(6): 665-673.

10. D’Ancona, G., Baillot, R., Poirier, B., et al. Determinants of gastrointestinal complications in cardiac surgery. (2003) Tex Heart Inst J 30: $280-285$.

11. Bolcal, C., Iyem, H., Sargin, M., et al. Gastrointestinal complications after cardiopulmonary bypass: Sixteen years of experience. (2005) Can J Gastroenterol 19(10): 613-617.

12. Aouifi, A., Piriou, V., Bastien, O., et al. Severe digestive complications after cardiac surgery under cardiopulmonary bypass. (1999) Can J Anesth 46(2): 114-121.

13. van der Voort, P.H., Zandstra, D.F. Pathogenesis, risk factors, and incidence of upper gastrointestinal bleeding after cardiac surgery: Is specific prophylaxis in routine bypass procedures needed? (2000) J Cardiothorac Vasc Anesth 14(3): 293-299.

14. D'Ancona, G., Baillot, R., Poirier, B., et al. Determinants of gastrointestinal complications in cardiac surgery. (2003) Tex Heart Inst J 30(4): 280-285.
15. Van Der Voort, P.H., Zandstra, D.F. Patho- genesis, risk factors, and incidence of upper gastrointes- tinal bleeding after cardiac surgery: Is specific prophy- laxis in routine bypass procedure needed? (2000) J Cardiothorac Vasc Anesth 14(3): 293-299.

16. Ait Houssa, M., Selkane, C., Moutaki Allah, Y., et al. Upper digestive bleedings after cardiac surgery. (2007) Ann Cardiol Angeiol (Paris) 56(3): 126-129.

17. Egleston, C.V., Wood, A.E., Gorey, T.F., et al. Gastrointestinal complications after cardiac surgery. (1993) Ann R Coll Surg Engl 75(1): 52-56.

18. Bhat, M., Larocque, M., Amorim, M., et al. Prediction and prevention of upper gastrointestinal bleeding after cardiac surgery: A case control study. (2012) Can J Gastroenterol 26(6): 340-344.

19. Taylor, P.C., Loop, F.D., Hermann, R.E. Management of acute stress ulcer after cardiac surgery. (1973) Ann Surg 178(1): 1-5.

20. Yoshida, K., Matsumoto, M., Sugita, T., et al. Gastrointestinal complications in patients undergoing coronary artery bypass grafting. (2005) Ann Thorac Cardiovasc Surg 11(1): 25-28.

21. Ait Houssa, M., Atmani, N., Nya, F., et al. Stress gastric ulcer after cardiac surgery: Pathogenesis risk factors and medical management. (2013) World J Cardiovascular Diseases 3(3): 312-316.

22. Jayaprakash, A., McGrath, C., McCullagh, E., et al. Upper gastrointestinal haemorrhage following cardiac surgery: A comparative study with vascular surgery patients from a single centre. (2004) Eur J Gastroenterol Hepatol 16(2): 191-194.

23. Christenson, J.T., Schmuziger, M., Maurice, J., et al. Postoperative visceral hypotension the common cause for gastrointestinal complications after cardiac surgery. (1994) Thorac Cardiovasc Surg 42: 152-157. 24. Behrens, R., Hofbeck, M., Singer, H., et al. Frequency of stress lesions of the upper gastrointestinal tract in paediatric patients after cardiac surgery: Effects of prophylaxis. (1994) Br Heart J 72(2): 186-189. 25. Katz, S.E., Kornfeld, D.S., Harris, P.D., et al. Acute gastrointestinal ulceration with open heart surgery and aortic valve disease. (1972) Surgeon 72(3): 438-442.

26. Lebovics, E., Lee, S.S., Dworkin, B.M., et al. Upper gastrointestinal bleeding following open heart surgery. Predominant finding of aggressive duodenal ulcer disease. (1991) Dig Dis Sci 36(6): 757-760.

27. Spotnitz, W.D., Sanders, R.P., Hanks, J.B., et al. General surgical complications can be predicted after cardiopulmonary bypass. (1995) Ann Surg 221: 489-496.

28. Simić, O., Strathausen, S., Hess, W., et al. Incidence and prognosis of abdominal complications after cardiopulmonary bypass. (1999) Cardiovasc Surg 7(4): 419-424.

29. Recht, M.H., Smith, J.M., Woods, S.E., et al. Predictors and outcomes of gastrointestinal complications in patients undergoing coronary artery bypass graft surgery: A prospective, nested case-control study. (2004) J Am Coll Surg 198(5): 742-747.

30. Perugini, R.A., Orr, R.K., Porter, D., et al. Gastrointestinal complications following cardiac surgery. An analysis of 1477 cardiac surgery patients. (1997) Arch Surg 132: 352-357.

31. Rey, J.F., Monnot, F., Lombart, J., et al. Endoscopic diagnosis and treatment of acute digestive bleeding in a cardiac surgical department. (1983) Acta Endoscopia 13: 109-113.

32. Shin, J.S., Abah, U. Is routine stress ulcer prophylaxis of benefit for patients undergoing cardiac surgery? (2012) Interactive CardioVascular Thoracic Surgery 1-6. 